\title{
O EXÍLIO DE POETAS BRASILEIROS NO CHILE DE ALLENDE: ESPERANÇA, DESILUSÃO E MEMÓRIA
}

\author{
Marcelo Ferraz de Paula ${ }^{1}$
}

\begin{abstract}
Resumo: Considerando passagens do exílio chileno dos poetas Ferreira Gullar e Thiago de Mello, este trabalho resgata, a partir da análise articulada de textos poéticos/memorialistas, a participação de ambos na construção do socialismo chileno, bem como a reação diante do golpe militar e o impacto do exílio, da violência de estado e da frustração política em suas produções literárias.
\end{abstract}

Palavras-chave: Ferreira Gullar, Thiago de Mello, exílio, comunitarismo, Allende

Abstract: Considering passages of the chilean exile of poets Ferreira Gullar and Thiago de Mello, this work retrieve from the articulated analysis in poetry and memoirists texts, involving the construction of chilean socialism and the reaction to the military coup and the impact of exile, violence of state and politic frustration in their literary productions.

Keywords: Ferreira Gullar, Thiago de Mello, exile, communitarianism, Allende

A passagem dos poetas Ferreira Gullar e Thiago de Mello, ambos perseguidos pela ditadura brasileira, pelo Chile coincide com um momento político sem precedentes na América Latina. A construção do socialismo era uma realidade euforicamente vivida por grande parte dos intelectuais chilenos e pela grande comunidade de exilados que ali chegavam em busca de refúgio contra as perseguições sofridas em seus países de origem. Ficando apenas em nomes brasileiros bastante conhecidos, podemos citar Paulo Freire, Mario Pedrosa, Fernando Henrique Cardoso, que, ao lado de tantos outros, encontravam-se asilados no Chile no começo dos anos 1970. O contexto político é conhecido por todos: Salvador Allende chegara ao poder como o primeiro governo declaradamente socialista eleito democraticamente na América Latina.

A esperança de mudanças efetivas alimentava o desejo de participação social tendo como horizonte a melhor distribuição de renda, a reforma agrária e

\footnotetext{
${ }^{1}$ Doutorando USP.
} 
a estatização das empresas estrangeiras. O triunfo upista (a Unión Popular que abrangia os partidos comunista, socialista e social-democrata) ampliava a já reconhecida tradição diplomática chilena de oferecer asilo político, ainda mais abrangente por conta da simpatia do novo governo em acolher as mais diferentes personagens de esquerda, alvos constantes das diversas ditaduras instauradas no continente. Sobre esta tradição chilena, vale mencionar um trecho do pomposo e hospitaleiro discurso de Pablo Neruda ao receber Thigo de Mello em seu país: “Chile acogió siempre al pensamiento perseguido. En eso estamos de acuerdo gobernadores e gobernados. El asilo contra la opresión no es solo un verso, es el laurel de Chile, nuestro común orgullo" (apud MELLO, 1984, p. 206).

A recepção de Thiago é amistosa, festiva, repleta de hospitalidade e carinho. Com base nela poderemos compreender, mais adiante, o tratamento fraterno que sua poesia dedicou ao país e a seus anfitriões neste período. $\mathrm{O}$ Chile já era para ele uma espécie de segundo lar. Amigos chilenos, e também brasileiros exilados, aguardavam a definição de sua situação no Brasil: a prisão, a liberdade e logo a necessidade de retornar para o país onde cumprira, até meados de 1965, missão como adido cultural. Por conta desta familiaridade com o país andino, esta segunda passagem é aparentemente menos traumática, uma vez que/pois o peso dilacerante do exílio é amenizado por uma vivência intensa, relativamente estável e segura, na qual está contemplado inclusive um papel político informalmente ligado ao poder central.

Por conta da atmosfera promissora - o testemunho de seus ideais sendo colocados em marcha num país latino-americano, a sensação de estar, de fato, escrevendo a história do continente - os livros que escreve neste período refletem a profundidade da conversão de sua poesia a instrumento para a luta política. São poemas que têm a vida mesma como matéria; não a vida especulada, hermética, inalcançável dos primeiros livros que publicou, ainda com fortes ecos da estética aristocratizante da dita geração de 45, mas sim a vida dos humildes, irmanados pelo empenho acolhedor de sua linguagem celebratória. A alegria passa a ser uma busca compulsiva: não há mais espaço 
para dores individuais, o compromisso com a construção de um mundo mais justo e fraterno torna-se o tema central, quase exclusivo, de seus escritos.

A linguagem poética busca no mundo social seu compromisso primeiro: poesia e vida formam um contínuo, alimentam-se um do outro, assumindo o compromisso quase profético de anunciar a emancipação humana, a liberdade e o amor. Se em Silêncio e Palavra (1951) dizia de maneira densa e algo enigmática "Somente sou quando em verso", agora, participando como entusiasta e espectador da construção da utopia socialista no Chile, escreverá sem margem para rodeios líricos:

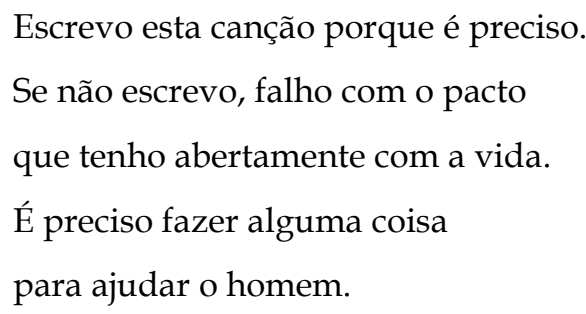

Mas agora.

O envolvimento de Thiago com parte da intelectualidade chilena e brasileira, em festas, encontros e projetos comuns ${ }^{2}$ gerava uma situação de vitalidade cultural e afetiva (inclusive por se apaixonar e casar com uma chilena) brutalmente oposta à vida do poeta Ferreira Gullar durante aqueles anos. A chegada do poeta maranhense a Santiago era marcada principalmente pela revolta. A maneira patética como seu nome fora lançado para a direção do partido comunista brasileiro, fato que lhe obrigaria a deixar o país, ainda lhe causava remorso e raiva. Depois veio a perseguição implacável do governo ditatorial, a prisão, a liberdade seguida de novas e graves ameaças da polícia política. Após um tempo como clandestino, segue em viagem para Moscou. O que seria um curso sobre marxismo de seis meses torna-se a primeira parte de

\footnotetext{
2 Um dos casos mais emblemáticos da atuação dos exilados brasileiros na construção do socialismo upista é o de Mario Pedrosa. O crítico de arte participou ativamente da construção do Museo de la Solidariedad, projeto artístico/político que envolveu a colaboração de figuras de primeira ordem da intelectualidade chilena e que contava com a participação efetiva do próprio Allende. Ver LOPEZ, Matias. "Ideologia e utopia no Chile: os usos sociais do exílio e da arte". In: Cad. De Pesq. Interdisc. Em CiS. Florianópolis, nº 98, jan-jun 2010.
} 
um longo exílio. Os meses que passou na Rússia, estranhando a língua, o clima, com saudades da família, contribuíram para que Gullar chegasse ao Chile já castigado pelo sentimento profundo de solidão e deslocamento. Pior que isso: sua chegada coincidia com uma nova fase da aventura socialista chilena. Começava a se dissipar a breve etapa de euforia pela vitória nas urnas e o governo de Allende, ao começar a colocar em marcha as mudanças prometidas, se deparava com um tecido social extremamente complexo, no qual as diversas forças que o levaram ao poder começavam a expor duramente suas divergências, abrindo espaço para uma encorpada investida reacionária.

Um dos capítulos do seu livro de memórias Rabo de Foguete (1998) oferece um painel objetivo e lúcido da tensão política que Gullar encontrou ao chegar ao Chile. Por se tratar de um livro de memórias, escrito anos após os acontecimentos narrados, quando "o tempo já aliviara os traumas"3, evidentemente as ideias e opiniões nele desenvolvidas dificilmente coincidem fidedignamente com as convicções do poeta no calor do momento. Pelo contrário, algumas conclusões a respeito da nebulosa conjuntura chilena que Gullar profere como simultâneas aos acontecimentos rememorados - sobretudo as de cunho mais negativo - quase nunca são compatíveis com os escritos que elaborou naquele momento. Não é nossa intenção, e nem poderia ser, decifrar a verdade dos fatos, desvendando o que o autor realmente acreditava, se no ceticismo trágico que figura na narrativa de Rabo de Foguete, ou numa esperança algo desconfiada - mas ainda assim convicta na defesa do projeto upista - que podemos ler em alguns poemas do período. O mais adequado nos parece ser entender o livro de memórias como um lúcido relato daqueles anos, com uma clarividência acumulada nos anos que se seguiram, sendo certamente difícil imaginar que qualquer intelectual envolvido no calor daquele momento tivesse uma opinião límpida, coesa e inflexível dos acontecimentos em curso. Tal esclarecimento se deve ao fato de, havendo um aparente descompasso entre o juízo contido em Rabo de Foguete (onde impera um olhar crítico, distanciado,

\footnotetext{
É o que diz o autor na apresentação do livro, reforçando o distanciamento temporal como anestésico do sofrimento vivido nos anos correspondentes ao exílio.
} 
apoiado no desenrolar futuro dos acontecimentos) e os poemas deste período (às vezes entusiastas das mudanças em curso, entregue ao momento presente e inserido na imprevisibilidade de toda ação política) ficaremos sempre com a verdade do poema, mais interessante e sintomática da experiência histórica nele contida.

Retornando desta necessária digressão, citamos uma passagem de Rabo de Foguete em que Gullar faz uma análise dos primeiros meses do governo socialista:

Um dos graves erros cometidos pelo governo socialista foi, logo de saída, dar uma aumento salarial de $100 \%$ a todos os trabalhadores do país, o que provocou o consumo desenfreado e o esgotamento de estoques. As prateleiras ficaram vazias e os preços subiram vertiginosamente. A necessidade de atender ao consumidor fez convergir para a produção de bens de consumo os recursos que deveriam dirigir-se para setores básicos da economia. Ao mesmo tempo, o esforço para suprir o comércio e minorar a escassez de mercadoria era frustrado pela ação sabotadora da burguesia, que comprava e estocava tudo que não era perecível. (...) Essa situação era gravada pelo bloqueio econômico imposto ao Chile pelos EUA. (GULLAR, 1998)

Gullar passou a viver num apartamento indicado pelo partido, com pouco contato com os outros brasileiros, numa solidão só comparável ao temor crescente de um golpe, já maquinado por alguns setores conservadores das forças armadas. É este o momento em que a pressão resultante do momento histórico começa a se mesclar com as lembranças da infância, com a saudade do país natal, amigos e familiares, num movimento de extrema importância na obra do poeta. Os poemas escritos durante o exílio afastam-se do tom popularnacionalista marcante nos Romances de Cordel (1964) e ainda visíveis nos primeiros poemas de Dentro da Noite Veloz (1976), como “Homem Comum”, 
"Poema Brasileiro", “Meu povo, meu poema" e "A bomba suja”. A matéria social passa a ser internamente mediada pela experiência particular do sujeito, erguida entre os escombros do desamparo, da ausência de afetos, enfim, na sensação de desconforto resultante do exílio.

O ano de 1973 é marcado pela escassez de produtos nas lojas, greves sucessivas e uma tensão social crescente. Os conflitos aumentavam os receios de um golpe militar iminente, que ganharia forma em setembro daquele mesmo ano. O país estava divido. Alguns dos intelectuais de esquerda, antevendo a violência da repressão militar, começam a deixar o país; outros, como Gullar, temem a perseguição decorrente do golpe. Os riscos são imensos, de ser preso, torturado e possivelmente assassinado como aliado de Allende ou de ser mandado para o Brasil, onde condições não menos aterradoras esperavam os militantes. Thiago de Mello ainda se irmana a uma eventual resistência, mas sua poesia, ainda que partidária da causa socialista, começa a perceber a delicadeza do momento:

$$
\begin{aligned}
& \text { Acho (escrevo no centro da desunião) } \\
& \text { que ainda pode se erguer um arco-íris. } \\
& \text { Mas também pode dar cupim no esteio } \\
& \text { da casa que é preciso edificar. } \\
& \text { Lá nos meus campos, onde a dor é a mesma, } \\
& \text { quando a chuva socava o chão cansado, } \\
& \text { se diz que um dia, um dia a casa cai. }
\end{aligned}
$$

No dia 11 de setembro de 1973 o teatro do golpe estava armado e o palácio de La Moneda era impiedosamente bombardeado. Allende se recusava a deixar o centro administrativo, mas a organização da resistência ao golpe mostrara-se inoperante e seria, para Gullar e Thiago alvo de duras críticas em seus poemas. Por fim o presidente fora assassinado, o general Augusto Pinochet assumia o poder dando início a uma das mais violentas ditaduras da América Latina. Na sequência do golpe, resta aos poetas, ainda incrédulos, levantar as inevitáveis perguntas: que ensinamentos a experiência da derrota deixaria na mente daqueles que a testemunharam? Como atuar diante da iminência da 
guerra civil? Quais os impactos daquele fracasso na luta que se desenvolvia em outros países da América Latina?

A derrocada do projeto upista torna-se, então, matéria fecunda para Gullar e Thiago. A última parte de Dentro da Noite Veloz, de Gullar, e todo o livro Poesia Comprometida com a minha vida e a sua, de Thiago, estão carregados de referências ao período: a experiência do exílio, no plano pessoal, e o testemunho da construção do socialismo e do golpe militar chileno, no plano histórico. Em um dos poemas deste período, Thiago de Mello revela a frustração diante da precária resistência ao golpe. O governo desarticulado, os aliados com medo do poder beligerante dos militares e as bases populares de apoio confusas, perdidas entre a defesa pouco promissora do regime e o conformismo diante da reação direitista, tudo isso apresentado a partir da ótica do exilado, com o olhar "de fora", mescla de desânimo e revolta:

\section{O que me espantou}

Não foi a multidão indo para casa (nós no meio dela, disfarçando), cabeça baixa, as pernas pesadas, seguindo a ordem que o inimigo lhe dava.

Eram operários, homens e mulheres.

Eram homens de todas as idades, subindo silenciosos a Grande Avenida.

Nenhum brado, nenhum braço erguido.

Nem foi a organização perfeita do inimigo,

a pontaria espantosa de seus aviões,

o rigor implacável do seu ódio.

Nem a ingenuidade dos que atenderam

ao turvo e meloso apelo

da monstruosidade humana

repetido pelo rádio.

Pois acreditaram na idiossincrasia, 


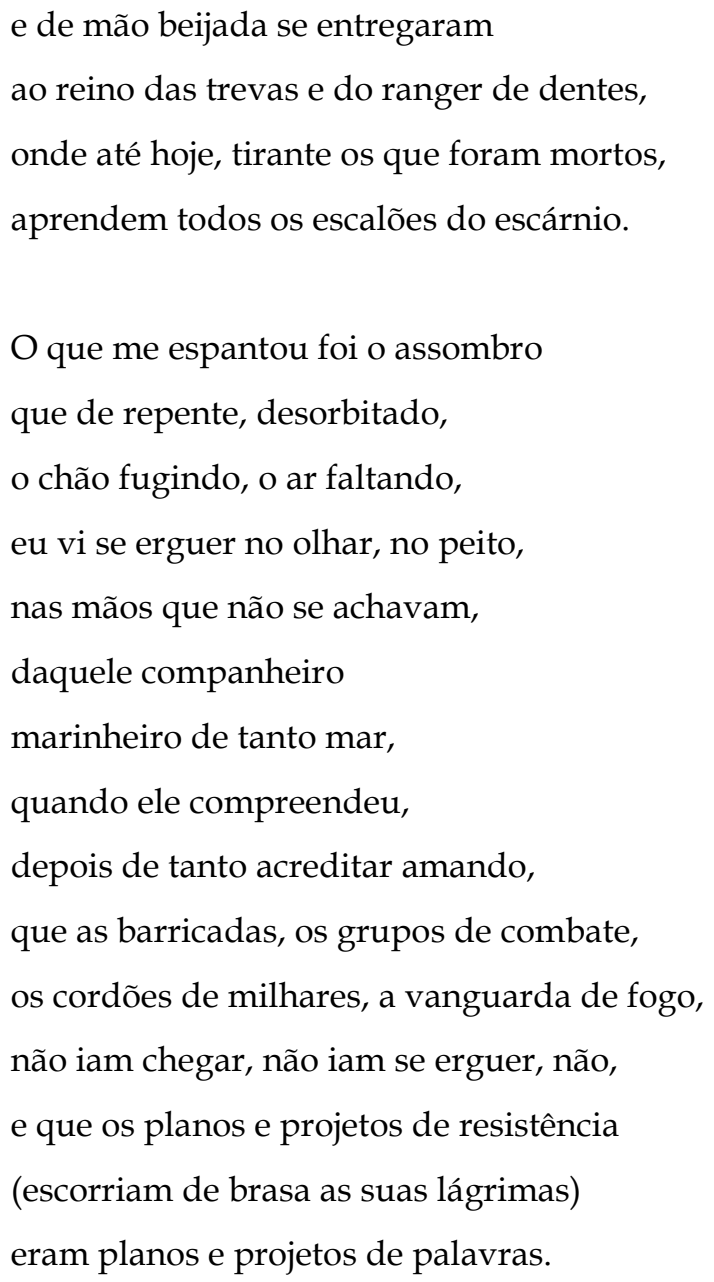

O poema é de uma abrangência notável. De modo denso percorre os principais dilemas anteriores à consumação do golpe militar de 11 de setembro. O olhar contém o leve traço da memória: o sujeito relembra o dia da morte de Allende; o tom é de avaliação, deixando solta a pergunta sobre o que de fato mais o abalou, intimamente, naquele momento em que a história do país, e de certa forma da América Latina, tinha uma importante página sendo escrita. Sem deixar transmitir afetação, a voz lírica percorre os fatos que ajudam a entender o horror do golpe: os militantes fieis a Allende, com os quais o sujeito se identifica, caminhando humilhados ("cabeça baixa, as pernas pesadas"), pequeninos diante da Grande Avenida; o poder de fogo do exército, antes menosprezado pelo governo socialista; a propaganda de direita nas rádios, conclamando os "cidadão de bem" a apoiarem o exército na "libertação" do país e os ecos estridentes da burguesia chilena, solidária ao golpe; e enfim, 
colocado como o espanto maior, a ilusão de uma resistência armada, a derrota sem luta, sem barricadas ou grupos de combate.

Vale notar, porém, que o espanto maior surge não da conjuntura apresentada (que para a historiografia são as situações que resumem o êxito do golpe) mas sim do desamparo individual, do companheiro privado de lutar, da derrota consumada sem a eclosão do combate, a princípio julgado necessário pelo sujeito do poema. Em outro poema, também de Poesia comprometida..., é a violência do golpe e o terror instaurado que são denunciados pela voz lírica:

\author{
Lá na Alameda de Bernardo O”Higgins \\ e no sangue chileno que escorria \\ dos corpos dos obreiros fuzilados, \\ levados para a fossa em caminhões \\ pela ferocidade que aos domingos \\ sabe se ajoelhar e cantar os salmos. \\ Lá na terra marcada como um boi \\ pela brasa voraz do latifúndio.
}

Mais até do que se dedicaram ao breve e tenso período de construção do socialismo no Chile, o desastre do golpe militar levanta questões de ordem individual e coletiva capazes de despertar nos poetas a necessidade de desenvolver um balanço da derrota, rever erros, reforçar conviç̧ões. Em alguns poemas de Dentro da Noite Veloz, de Gullar, e Poesia comprometida..., de Thiago de Mello, sobretudo em sua segunda parte, denominada "Lição de Cordilheira", temos encenado o complexo de ascensão e queda, conforme pensado por Benjamin Abdala Junior (2003) ao propor uma chave de leitura para o mito de Ícaro:

Importa é reproduzir no gesto o princípio de juventude que embala não propriamente o preconcebido vôo trágico da personagem mitológica, mas a possibilidade de esse princípio se reconfigurar - pela práxis individual e coletiva - em novos e contínuos vôos, pois que a queda não é necessariamente 
definitiva - um rito circunscrito à repetição sem história. No limite, quem se embalou pela corrente "quente" da utopia - a busca autêntica da felicidade - pode se ver, após deparar-se diante da evidência de fulgurações mais amplas, em movimento de queda. (ABDALA, 2003, p. 30)

O peso desalentador da experiência chilena é formulado por estes poetas em sintonia com a interpretação que Abdala dá ao processo social e cultural. Assim como a queda de Ícaro, ao alçar seu voo sem seguir os conselhos de equilíbrio e prudência oferecidos pelo seu pai, Dédalus, que o aconselhava a voar somente em alturas medianas, para que o calor do sol não ofendesse suas asas de cera, da mesma forma a experiência histórica testemunhada pelos poetas no Chile representa um intervalo entre o choque da utopia desfeita (consciência da imprevisibilidade concernente a toda atividade política) e a busca de energias para definir novas decolagens. Vencido o projeto político que mirava a justiça social pregando a transformação profunda da sociedade chilena, cabe aos autores recolher dentre os escombros deste projeto um sentido para aquela experiência social. O momento de revisão é complexo e dramático, se prolonga em vários poemas e altera o estatuto lírico de suas obras seguintes.

Tanto que após este balanço crítico, que também pode ser compreendido como uma espécie de luto decorrente da decepção frente a queda de Allende, a ótica do sujeito destas duas poéticas se altera. Thiago de Mello elabora uma ressignificação daquela derrota, transformando, bem ao gosto de seu temperamento poético, Allende em herói de uma luta que prossegue, malgrado a queda ali presenciada. Por sua vez, o movimento de Gullar é mais complexo, visa estabelecer um reencontro com a subjetividade, ampliando seu espaço de militância e mantendo sua integridade humana em meio às ruínas da utopia abalada. Parece ser exatamente este o movimento iniciado nos últimos poemas de Dentro da Noite Veloz, consagrado no Poema Sujo, e gradativamente corroborado em sua poesia, ao ponto de alcançar nos livros mais recentes uma inquestionável distância dos temas sociais mais imediatamente voltados ao que se costuma definir como uma postura de engajamento político. Tal movimento 
é previsto por Abdala, que o demarca como resposta possível, e válida, diante de uma etapa de refluxo histórico: "Uma das estratégias, para se preservar, pode ser contrair-se, fixando numa ilha pessoal" (ABDALA, 2003, p. 32)

Se levado a cabo na profundidade que o processo histórico exige, a reflexão poética destas quedas irá muito além da escolha de vilões e traidores, não se contentará em execrar os líderes ou tampouco convertê-los em mártires, seguindo a falácia militante de converter uma derrota concreta em vitória abstrata. Para que o movimento dialético de ascensão e queda atinja sua plenitude crítica, ele necessariamente precisa se voltar para a própria ideologia. Por isso, numa poesia controversa como a de Thiago de Mello, teremos momentos de entrega demasiadamente simplista à causa defendida, hasteando uma confiança pouco convincente em redenções, como ocorre na dedicatória da "Lição de Cordilheira":

\footnotetext{
A Salvador Allende,

o fogo comendo,

o sonho cantando.

O povo vai fazer o resto.
}

Ou avaliações deste período que optam pelo didatismo, com resultados que se assemelham ao prosaísmo dos discursos oficiais da esquerda derrotada:

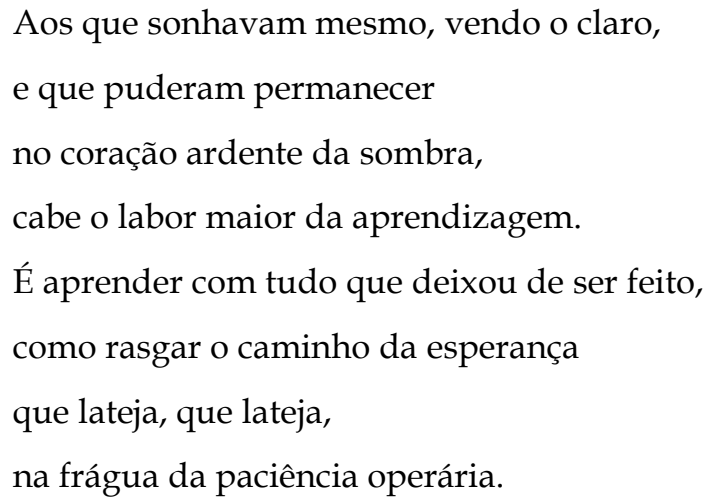

Em outros momentos, no entanto, o poeta alcança passagens de grande sensibilidade, deixando transparecer, entre as ruínas daquele fatídico setembro, "quando poderia ser a primavera", os caminhos que sua obra - e aqui 
lembramos do seu esforço em fundir obra e vida num todo coeso e solidário almeja seguir para além dos acontecimentos político-sociais imediatos, isto é, quando a falibilidade da experiência humana oferece sentido e beleza à ideologia: pois, medita o poeta, "que avançar neste chão ferido seja/ também saber o que fazer de mim".

Em outros termos, podemos afirmar que a experiência vivida por Thiago de Mello no período em que cumpriu seu exílio no Chile (entre 1966 até 1973, quando seguiu para a Europa) foi de aprofundamento de sua obra na questão social. Sua militância poética tornou-se ainda mais intensa a partir deste período, marcada pela esperança de construção do socialismo no país andino e pela amizade com diversos membros da intelectualidade esquerdista do Chile e do Brasil por lá exilados. O baque sofrido com o golpe militar é tratado com grande interesse pela sua poesia e é visto de maneira ambígua, ora como uma derrota dolorida que expunha os erros da Unión Popular, mas que não chegavam a botar em dúvida a validade de suas convicções, ora como um aprendizado necessário, "uma semente que não sabe que abre um rastro de luz na escuridão".

Obviamente teremos acentuadas neste período as diferenças estrondosas entre o temperamento poético dócil, cúmplice do leitor, característico de Thiago de Mello, e a poética vertiginosa de Ferreira Gullar. Como tratamos no início desta reflexão, o exílio de Gullar mostrou-se particularmente degradante; assombrado pela saudade da família, longe dos amigos, gradativamente descrente da forma como se entregara, anos antes, ao radicalismo politicamente utilitarista de sua poesia, Gullar acabou por incorrer num mergulho alucinado nas memórias da infância, oferecendo uma nova dinâmica a sua busca pela expressão.

Tanto que no já mencionado livro de memórias, sua conturbada saída do Chile, enquanto vivenciava o risco praticamente mortal de cair nas mãos do governo, aquela altura provisório, de Pinochet, a sensação descrita pelo poeta é de aflição e ressentimento: "tinha que sair daquele maldito país antes que fosse tarde demais" (GULLAR, 1998, p. 185). O exato oposto das posteriores 
representações do Chile na obra de Thiago de Mello, sempre marcadas pela camaradagem, a beleza das cordilheiras e a luta eufórica pelas mudanças em marcha, como vemos no poema memorialístico "Chile":

(...)

Mais que gota de pétala, és o mar denso,

brisa da noite, vento de verão, neve de cordilheira, a lava ardente e doce da ternura que tua gente nos âmagos da vida me gravou.

De todo o meu caminho percorrido pelas quatro estações de tua luz, entre ágatas, estrelas, lápis-lázulis, guardo a manhã dos pêssegos floridos, as fondas, as bandeiras de setembro, pastel de choclo, cazuela de congrio, Neruda e a noite de Valparaíso, Nemésio e seu taller 99,

Prado e seus volantines, Violeta e sua guitarra e todo o povo cantando na Alameda a reconquista do pão e da luz manancial da liberdade.

(MELLO, 1996, p. 98-99)

Retomando o poema de Gullar, observamos que nele a queda de Allende é vista de uma perspectiva prioritariamente pessoal: no dia do golpe, Gullar tivera a entrada de sua residência pintada com a palavra "comunista", como um sinal de que os vizinhos conheciam sua atuação, o que significava grandes riscos devido a "caça às bruxas" realizada pelas forças militares golpistas, prontas para arrasar os simpatizantes do socialismo upista. O temor de ser denunciado é a tônica de seus poemas, com passagens de terror e aflição, encadeadas no limiar da expressão, verbalizando o pânico da existência ameaçada:

Ao nível do fogo

entre fogos (em Santiago

do Chile, em Buenos Aires, em)

falo

à beira da morte

como os vegetais

com seu motor de água

como as aves 
movidas a vento,

como a noite (ou a esperança)

com suas hélices

de hidrogênio

Esta presença constante da morte rondando o poeta que escreve, na ânsia de se exprimir por completo antes da extinção iminente, está no gérmem de todo o Poema Sujo, a obra máxima do poeta maranhense. Ameaçado por todos os lados, no cerne da tensão social vivida no Chile, Gullar observa o impasse histórico de um ângulo no qual os acontecimentos políticos, as convicções, a revolução, tornam-se impulsos externos filtrados, ou melhor, vitalmente absorvidos, pelo sujeito preso ao seu tempo e a sua condição de exilado.

Ainda em Rabo de Foguete, Ferreira Gullar analisará as lembranças do golpe militar chileno de maneira severa e contundente. Ao acompanhar de longe as aventuras do governo socialista, mais como um refugiado do que como um intelectual atrelado ao projeto upista, Gullar é quem fará as avaliações mais duras daquele período de intensa mobilização:

Contrário à escolha da via armada para chegar ao poder, eu testemunhara no Chile o fracasso da via pacífica. Que conclusão devia tirar daí? Que não havia como chegarmos ao poder, que a revolução era inviável? Já antes, diante das dificuldades enfrentadas por Allende para fazer a avançar o processo socialista, me perguntara se nós, comunistas brasileiros, devíamos continuar a pagar preço tão alto para chegar ao poder, uma vez que chegar a ele não significava dar melhores condições de vida ao povo e sim, em vez disso, a curto prazo pelo menos, empurrar a sociedade para uma luta fratricida de resultado imprevisível. Agora eu conhecia o resultado: a derrota. (GULLAR, 1998, p. 198-199)

O discurso deste Gullar que narra as lembranças do exílio, já no final dos anos 90, aponta o testemunho do golpe chileno como uma passagem fundamental para justificar seu desencanto com o ideário socialista. A 
fragilidade do governo de Allende, seus erros sintomáticos, a falta de coesão do operariado para organizar uma resistência (queixa também presente no poema de Thiago) foram elementos tomados em Rabo de Foguete como justificativa histórica e biográfica para que o poeta abandonasse a militância poética e se afastasse gradativamente dos ideais socialistas, até renegá-los por completo.

Relembramos, entretanto, que a leitura das memórias deve ser feita com os cuidados indispensáveis para se analisar este gênero literário. Estamos diante de uma versão dos acontecimentos narrados; o simples fato de estar presente como testemunha dos acontecimentos não confere um valor de verdade ao relato. Ao comentar as particularidades deste "quase-romance memorialista", David Arrigucci diz que "não prevalece, como se poderia esperar, a perspectiva de quem escreve depois que as coisas já deram e a história, sabida de todos, já é outra" (ARRIGUCCI, 1998). A constatação, todavia, deve ser aplicada basicamente à estratégia narrativa utilizada por Gullar na elaboração do livro. A construção do livro coloca em primeiro plano o olhar do sujeito no centro dos acontecimentos, transformando-o num personagem e dando profundidade literária ao livro, que certamente revela cuidados narrativos que vão além do mero relato autobiográfico.

Entretanto, transposta para fora do ponto de vista narrativo, a crença de que o livro, de fato, recupera com precisão as impressões do narrador-Gullar no período ali abarcado, só poderia soar como farsa. Tampouco podemos perder de vista que o próprio gesto de lembrar, a memória em si, é virtual e falível, ou seja, acompanha as mudanças da visão de mundo do sujeito, podendo, é claro, alterar as percepções do passado, ainda quando não há uma intenção deliberada.

É importante insistirmos nestas considerações antes de lermos os "Dois poemas chilenos", presentes também em Dentro da Noite Veloz e escritos no calor dos acontecimentos.

\section{Dois poemas chilenos}




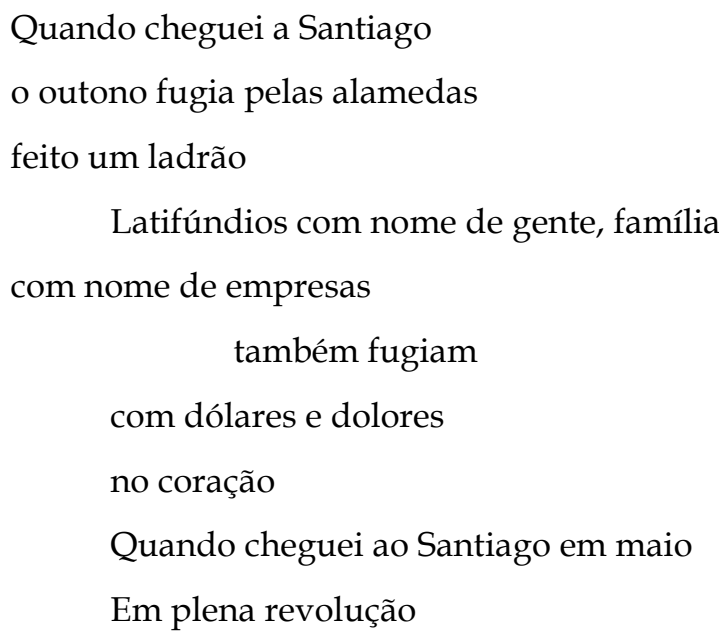

\section{II}

Allende, em tua cidade

ouço cantar esta manhã os pássarinhos

da primavera que chega.

Mas tu, amigo, já não os pode escutar.

Em minha porta, os fascistas

pintaram uma cruz de advertência.

E tu, amigo, já não a podes apagar.

No horizonte gorjeiam

esta manhã as metralhadoras

da tirania que chega

para nos matar

E tu, amigo,

já nem as pode escutar.

Observamos que o juízo do sujeito lírico diante dos acontecimentos é menos negativo do que aquele concebida posteriormente na escritura das memórias. Allende é enunciado como "amigo" - destacada, entre vírgulas, numa posição que pode ser tanto a de vocativo como a de aposto, quebrando o ritmo fluente do poema, além de repetida como uma espécie de epíteto - a voz lírica é solidária ao líder tombado. A imagem da primavera - particularmente 
fecunda pela data do golpe, ocorrido no início de setembro - aparece, assim como no verso já citado de Thiago de Mello, como imagem de uma redenção esvaziada (agora são as metralhadoras que "gorjeiam", em chave irônica do antológico poema de exílio de Gonçalves de Dias, perseguindo os aliados do socialista). Não há heroísmo, é certo; Allende é a própria imagem do fracasso, morto, já não pode dar continuidade ao seu projeto e ouvir o mundo, a esperança, que segue viva na imagem dos passarinhos, símbolos da liberdade, que voam na primavera. Vencido, não pode também, como mostra a versão paralelística do verso final, escutar o cortejo violento dos sonhos ali semeados. A aventura chilena está finda, deixando na queda a exigência de novos voos, em outros cantos.

\section{Referências Bibliográficas:}

ABADALA JR., B. De vôos e ilhas. São Paulo: Ateliê, 2003.

ARRIGUCCI, D. “Tudo é exílio". Jornal de Resenhas. Folha de São Paulo, novembro de 1998.

GULLAR, F. Toda Poesia. Rio de Janeiro: José Olympio, 2007. . Rabo de Foguete. Rio de Janeiro: Revan, 1998. . Em Alguma parte Alguma. Rio de Janeiro: José Olympio, 2010.

LOPEZ, Matias. “Ideologia e utopia no Chile: os usos sociais do exílio e da arte". In: Cad. De Pesq. Interdisc. Em Ci-S. Florianópolis, nº 98, jan-jun 2010.

MELLO, T . Vento Geral - poesia reunida. Rio de Janeiro: Civilização Brasileira, 1984.

NERUDA, P. “Desde que Thiago llegó a Chile...". IN: Mello, T. Vento Geral. Rio de Janeiro, Civilização Brasileira, 1984. 